\title{
XXXII. Materials towards a more intimate knowledge of native molybdena, containing a very advantageous method of extracting molybdic acid from that sulphuret
}

\section{C.F. Bucholz}

To cite this article: C.F. Bucholz (1803) XXXII. Materials towards a more intimate knowledge of native molybdena, containing a very advantageous method of extracting molybdic acid from that sulphuret, Philosophical Magazine Series 1, 16:63, 193-204, DOI: $10.1080 / 14786440308676325$

To link to this article: http://dx.doi.org/10.1080/14786440308676325

$$
\text { 曲 Published online: } 18 \text { May } 2009 .
$$

Submit your article to this journal ए

\section{山ll Article views: 3}

Q View related articles ¿ 


\section{[ 193$]$}

XXXII. Materials towards a more intimate Knowledge of Native Molybdena, containing a very advantageous Method of extracting Molybdic Acid from that Sulphuret. By C. F. Bucholz $*$

A

After the repeated labours of a great many chemists, such as Quist, Scheele, Bergman, Heyer, Ilsemann, Pelletier, Richter, \&c. on sulphuret of molybdena, both in regard to a better method of extracting molybdic acid from that mineral, and in regard to the phynomena it exhibits with other bodies, one might believe that no further researches remain to be made on this subject. But by reflecting properly on what has been done, we shall soon be convinced of the contrary. As my principal object in this memoir is to make known a more advantageous method of preparing molybdic acid, it will be requisite, to justify the necessity of such a method, to recapitulate the old and new processes, in order to show their defects, and to compare them afterwards with mine.

The first process for extracting molybdic acid from molybdena consists in separating the sulphur from the molybdena by a strong heat, and converting the remaining metal into acid by continuing to heat it in the air. The vapours of the molybdic acid are received in a proper vessel, where they are condensed under the form of ycllowish white scales, which are alone considered to be molybdic acid. As these scales are formed very slowly and in small quantity, and as the volatility of the molybdic acid in a moderately strong heat on the one hand, and on the other the property of the same acid of fusing in a very strong heat, and of penetrating, during its fusion, the matter of the crucible, render it impossible to obtain in this manner a certain quantity of acid, this method cannot in any point of view be considered as advantageous or even practicable: we shall therefore proceed to examine the second method.

The second process, which like the first belongs to Scheele, consists in distilling off at diferent times nitric acid of a moderate strength from molvbdena until the sulphur and the metal are both converted into acid. This operation requires from 20 to 24 parts of nitric acid for one part of sulphuret of molybdena, and it leaves with the molybdic acid the iron and earths which the purest molybdena

* Froin Scherer's Alicrmeincn Fournal der Chemie I 802, no. 5. p. 48 5,

VoL. XVI. No.63.

$\mathrm{N}$

always

August 1803. 
always contains in greater or less quantity. This process, which was considered as the only one proper for obtaining purc molybdic acid, besides-its not answering the proposed end, is too expensive to be followed, and therefore another more occonomical and more proper for obtaining an acid free from foreign mixture is desirable to be substituted in its stead.

The third process consists in distilling the sulphurated molybdena with arsenic acid, and in expelling by volatilization the oxide and sulphuret of arsenic which are formed. This method also is so expensive alsd so dangerous that we shall not enter into any further discussion of it.

The fourth process, which belongs also to Scheele, is that which furnishes the acid in the speediest manner; but it does not furnish it pure. It consists in causing the molybdena to deflagrate with nitrate of potash in proportions respecting which authors vary. Scheele* took four parts of nitrate to one of sulphuret of molybdena ; Lampadius $†$ recommends six parts of nitrate to one of molybdena, and Fourcroy $\$$ three parts of nitrate to one of molybdena.

The sulphur and the metal are here converted into acids, and in that state combine with the potash. A portion of the nitrate remains undecomposed, and there is formed at the same time deoxygenated nitrate: the remaining mass is dissolved in warm water; and the molybutate of potash, still mixed with its other salts, is decomposed (or this may be done after it has been separated by crystallization) by mcans of the nitric, muriatic, or sulphuric acids. The nolybdic acid, when the solution is not too dilute, separates under the concrete form: this precipitate is not pure molybulic acid, but, as Scheele before announced, molybdic acid holding potash, or, according to Fourcroy, acidulous molybdate of that alkali.

This acidulous molybdate is much inore goluble in water than pure molybdic acid, which for its solution requires 500 parts of that liquid, whereas acidulous molybdate dissolves in three or four parts of water. The latter fuses in the fire sooner than the acid, and more readily corrodes the crucible. After cooling, it is of a beautiful yellow colour: the acid, on the contrary, exhibits a radiant mass of a whitish gray colour, having a slight metallic brilliancy. The acidnlous molybdate does not suffer itself to be sublimated; whereas the pure anid is vaporized by heat, and deposits it-

\footnotetext{
* Opuscula Physica et Chemica, tom. i. p. 202.

+ Handbucli der Chemischen Analyse, p. 325 .

* Systême des Connoissances Chimiques.
} 
self, on cold bodies presented to it, under the form of needles and yellow scalcs. It appears that acidulous molybdate has often been employed for pure molybdic acid. Thus Lampadius gives reason to believe that the acid which he prepared by the above process was not pure acid but acidulous molybdate. He recommends decomposing the mass which remains atter deflagration by muriatic acid in excess. It will be scen by the following experiments that the molybdic acid caniot be entirely freed from the potash. To remove this obstacle to the preparation of pure inolybdic acid, Scheele recommends dissolving the precipitate obtained in the smallest quantity of water possible, and boiling it for some minutes with a new quantity of nitric acid.

When the alkali has been thus separated, the molybdic acid is supposed to deposit itself in very small crystals. It appears to me confirmed that in this manner there is separated a little pure acid; but the very large part of the acid which remains dissolved with the acid added in excess is obtained separately with rery great difficulty; and when enough of acid is not added, a mixture of pure acid and acid holding alkali is obtained. As this fourth process appeared to me far preferable to the rest, bcing much shorter and. more œconomical, I wished to try whether it was not possible still to improve it, and to render it common in the preparation of the molybdic acid.

As the propurtion of nitre, even in the process of Fourcroy, appeared to me still too great, I was desirous to examine whether something might not be saved in this point of view.

\section{Experiment I.}

I heated to redness in a IIessian crucible six gros of saltpetre, and projected on it, in parts, pure sulpburated molybdena pulverized. After I had added two gros and twenty grains of this mineral, the deflagration was still very brisk. I maintained the matter in fission for some minutes longer, after which I dissolved the mass in water. The solution was complete, a few grains of oxide of iron and of silex excepted. On proceeding to the crystalization of the salts contained in this mass, I obtained some small crystals of undecomposed nitre.

\section{Experiment II.}

According to the indication furnished by the preceding experiment, I took two pounds three quarters of purified nitre, which I brought to red fusion, and gradually projected on it a pound of pulverized sulphuret of molybdena. 
When the whole quantity of molybdena was introduccd, a very brisk deflagration took place. I dissolved the saline mass in distilled water. The whole dissolved except about ter gros, which were oxide of iron and silex. The ley furnished by crystallization a little undecomposed saltpetre, nitrite of potash, and gaso-nitrous sulphates and molybdates of potash, or holding initrous gas.

These experiments prove that $2 \frac{3}{4}$ parts of nitre are sufficient to deprive of its sulphur one part of sulphurated molybdena, and to oxysenate the metal. This quantity might even be diminished, were it not to be apprehended that the small portion of undecomrosed eulphur which is found in the mass towards the end of the operation would with difficulty be attacked by too small a quantity of mitre.

'To find the means of separating the molybdic acid from the acidulous molybdate of potash thus obtained, I made the following experiments.

\section{Experiment III.}

To a portion of the above solution I added sulphuric acid till nothing more was precipitated and the mixture had acquired a strongly acid taste, after which it was digcsted cold for two hours. The precipitate obtained was washed several times with distilled water, and it was heated with twenty parts of the same water. The whole of it readily dissolved.

To this solution I added nitric acid until there was a considerable excess. No precipitate was formed. I evaporated the liquor to dryness. The residuum contained no crystallized part, had no tiaste of saltpetre, and did not deflagrate when thrown on burning eoals. This residuum, which was yellow, easily fissed in an ignited crucible without being evaporated by a sirong heat. After cooling, it was found to have assumed a yellower colour. This experiment evidently proves that acidulous inolybdate of potash is not decomposed either by sulphuric acid assisted by a digesting heat, or by nitric acid; for the precipitate obtained was exceedingly soluble, and was not volatile at a white heat.

As I had evaporated the solution of molybdate conjointly with nitric acid, it was possible that the nitrate of potash formed in the first instance might afterwards be decomposed by the molybdic acid separated. I therefore resulved to repeat the same operation with nitric acid.

\section{Experiment IV.}

1 decomposed a part of the above solution of acidulous 
molybdate, adding an excess of nitric acid. A large portion of the precipitate was redissolved. After some hours digestion I tried the nature of the precipitate, after having collected and washed it on a filter. On putting a little of the precipitate, still moist, into a Hessian crucible, and cxposing it to beat, it resulved itself into a transparent liguor. When the whole inoisture was dissipated, and the crucible had beyun to be red, the matier entered ivto fusion; but only a very weak volatilization was observed by an increase of heat. The fused mass was of a reilowish yay colour. A great part of it bad passed through the cracible. It resulted from these phenomena, compared with those which the free acid exibibited with water and in the fire, that the precipitate obtained in this experiment was a mixture of tree nolybdic acid and acidulous molybdate of potash.

After this imperfect success I resolved to try the muriatic acid to decompose aciatilous molybdate of potash.

\section{Experiment $\mathrm{V}$.}

I decomposed the abore-mentioned solution by means of muriatic acid. An abundant precinitate was furmed. I added a strong excess of acid, which dissolved a remarkable quantity of the precipitate. I disested the mixture for some hours in a wam place, which completed the solution of almost the whole it. After cooling, there was formed in the Jiquor a considerable number of very small crystals. I tried these crystals, and found that they were amost entirely soJuble in three or four parts of warm water ; that they readily fused in an ignited crucible without cmitting much vapour; that they penetrated the matter of the crucibie; and that after cooling they had a grarish ycllow colour, I thence concluded that the precipitate obtaincd by the muriatic acid contained scarcely any free acid, but was almost entirely composed of acidulous molybdate. I then eraporated to one-half, in a moderate heat, the solution which still contained molybdic acid. During the evaporation, but in particular after cooling, there was separated a quantity of small yellowish white crystals : there, however, remaincd in the solution a still greater quantity of molybdic acid, as was indicated by its acid taste and the trials to which it was subjected. The crystals obtained exhibited the same phanomena with water, and in the fire, as pure molybdic acid.

These experiments did not furnish a method of preparing, with safety and advantage, purc molybdic acid, and of obtaining the whole quantity contained in the sulphurater 
molybdena; or there was formed acidulous molybdate of potash which was not decomposed; or only a little molybdic acid was separated; or there remained in the liquid too large a quantity of acid, which could be separated only incompletely and with difficulty. In this unfavourable state of things I thought of several means for decomposing the molybdate by the help of double affinities, but I was not able by any of the known means to separate the acid completely from the alkali. I therefore resolved to recur to the old method, which consists in oxygenating the sulphuret by nitric acid, taking care to correct the process by separating the greater part of the sulphur by calcination. By this preliminary separation of the sulphur a great quantity of the acid is saved, and the labour is considerably shortened. I consequently proceeded to calcination in the following manner,

\section{Experiment VI.}

Five ounces and a half of sulphuret of molybdena in fine powder, and which were perfectly pure, a few small particles of quart $z$ and oxide of iron excepted, were introduced into a large Hessian crucible, which, for the greater convenience, was placed obliquely in a furnace and surrounded by charcoal. When the matter was red it was stirrcd incessantly, and in turns, by me and my friend M. Haberle, to whom I was indebted for the molybdena employed in these different experiments. During the first hour, and before the greater part of the sulphur was dissipated, the matter retained its lightness: it then united into a mass, and its black colour passed successively to gray, reddish gray, and then to whitish gray.

When the whole sulphurwas driven off, which required two hours, the mass by an increase of heat coagulated more and more, and even began to fuse at the bottom of the crucible, and it appeared by the vapour which rose that the molybdena was volatilizing. Having maintained a moderate fire for half an hour, I took the crucible from the fire and examined the matter. It had a whitish gray colour, exhibited here and there splendour and a crystalline form, and weighed a little more than four ounces; which approaches nearer to the $0 \cdot 23$ of sulphur which Lampadius said he found in molybdena than the proportion of Kirwan, which is 0.55 . The sensible metallic taste of the calcined matter, its brilliant and cry alline aspect, and the experiments made by Ilsemann *

Crell's Chemische Annalen 1787 , vol. i. p. 410. 
and Iever*, in which calcined nolybdena exhibited the phanomena of an acid, made me suspect that this molybdena might be molybdic acid like that sublimated. In this case the nitric acid might have been spared; which would have rendered the process still shorter and more ceconomical.

To clar up wy doubts in this aespect I male the following preliminary experiments.

\section{Experinent VII.}

1 reduced to the powder some grains of calcined molybdena, poured over it a gros of water, and heated it above a lamp. I then instilled into it some drops of a solution of carbonate of soda: on each new instillation a strong effervescence tork place, and a great part of the matter was dissolved. For the moment this result was sulficient to enable me to conclude from it the acid nature of the calcined molybdena. The solution was filtered, and decomposed by nitric acid. There was formed a precipitate of molybdie acil, which placed it beyond a doubt that there was furmed a combination of this acid with soda.

\section{Experiment VIIL.}

I pulverized some grains of calcined molybdena, and boiled them for some minutes with an ounce of water. The taste of the liquor, which was sensibly acid and metallic, ais well as the red colour it communicated to turnsole paper, again proved the nature of the acid of calcined molybdena.

It gave me great satisfaction to have found so short and so ceconomical a method of obtaining molybdic acid. I cannot help wondering, as the experiments of Scheele, Heyer, and Ilsem: nn, have been so long known, that chemists have not followed this method indicated to us by the nature of calcined molybdena, and to which they had so nearly approached. In order to ascertain more fully whether calcined molybdena is pure molybdic acid, and to determine the means of separating from it the heterogeneous substances with which it might be still combined or mixed, I made the following experiments.

\section{Experiment IX.}

As the molybdic acid has the property of combining easily with a portion of potash, and of retaining that base', if not entirely, at least in a great part, against the action of all acids, this salt could not be of any use for purifying that

* Crell's Chemische Annalen, vol, ii. p. 26 and 825 . 
acid. The alkaline earths, and earths which with the molybdic acid form salts difficult of solution, could not answer my purpose to separate the acid from the insoluble substances with which they are mixed. It remained to try soda and ammonia, which I found to be both equally proper under circumstances peculiar to each of them, for accomplishing the proposed end.

\section{Experiment X.}

I boiled two gros of calcined molybdena with eight ounces of water, and instilled into the solution a ley of carbonate of soda until no more cffervescence took place. An excess of alkali was added, and the matter was left to boil for half an hour: it was then filtered, and the concrete matter which remained on the filter was cdulcorated. The different liquors were evaporated to two ounces, and nitric acid to excess was instilled into the warm liquid. During the instillation of the nitric acid a crystalline white powder was deposited, and after cooling there were formed in the liquor crystals of a certain size. A new quantity was obtained by evaporation. The different salts were washed and dried. The residuum on the filter, after being washed and dried, weighed thirty grains, and had the reddish colour of oxide of iron.

\section{Experiment XI.}

The preceding experiment was repeated, with this difference: the liquor, after the effervescence had ceased, was boiled for half an hour longer. The matter, after being reduced to two ounces, and filtered, was suffered to cool before the nitric acid was added. The addition of this acid caused to be precipitated a larger quantity of the white powder, which had a more crystalline aspect, and which after edulcoration and desiccation had the splendour of motherof-pearl. As I did not add so much acid in this experiment as in the former, the liquor was less charged with molybdic acid. The residuum, when washed and dried, weighed also thirty grains.

As I suspected that this residuum might contain a portion of molybdic acid less soluble than the preceding, I tricd to extract this acid by boiling the residuum with nitric acid, With this view I made the following experiment.

\section{Experiment XII.}

The thirty grains of the residuum of the two last experiments were boiled with an ounce of nitric acid of the specific gravity 1.250 and half an ounce of water, until the whole 
whole moisture was dissipated. Duing the evaporation I observed no disengagement of nitrous gas, from which I could conclude that there was in the residuum a little molybdena not yet acidified. I then poiled the residum for halt an hour with a ley of carbonate of soda, alter which there was added to the solution nitric acid to decompose it; but I observed no precipitation of molybdic acid, though an excess of nitric acid had been added. The solution had only a metallic acid taste. On examining the residuum more closely, it was found to be composed of alumine, oride of iron, and a few fragments of silex, which, if I except the oxide of iron contained in the sulphurated molybdena, arose in part from the molybdena and partly from the crucible.

\section{Experiment XIII.}

The white precipitates of experiments X. and XI. were put into an ignited crucible. By an increase of heat they first entered into fusion, and were then volatilized and condensed, partly under the pulverulent form and partly under the crystalline. By continuing the fusion the matter penetrated through the crucible. The fiuseci matter was very liquid, and on cooling it formed itself into a crystalline radiaut mass of a whitish gray colour having a slight metallic splendour. In other respects it exhibited the same phænomena as pure molybdic acid.

This last method furnishes a very short and neconomical method of obtaining molybdic acid. There can be no doubt that if the molyodena had been entirely free fiom matrix the calcined mass would have entirely dissolved, except an atom of iron, from which sulphuret of molybdena is never free.

I was desirous also to try the separation of the molybdic acid by the help of ammonia. With this view I made the following experiments.

\section{Experiment XIV.}

I digested for twelve hours, in a moderate haat, a gros of the calcined mineral in fine powder with half an ounce of concentrated liquid ammonia, shaking the matter from time to time; after which the liquor was filtered. It had still a strong odour of ammonia. The half of it was decomposed by nitric acid, which precipitated from it molybdic acid in abundance. The other half was evaporated in a small porcelain capsule, aud then heated to a slight degree of incandescence. The ammonia was entirely dissipated, and lift a grayish blue residuum, which entered into fusion 
in a stronger heat, and which, after cooling, exhibited a radiant whitish gray mass perfectly similar to fused pure molybdic acid. The residuum collected after the digestion of the calcined molybdena with the ammonia weighed twenty grains: I subjected it to the following experiment.

\section{Experiment XV.}

I boiled the residuum above mentioned with two gros of nitric acid to perfect evaporation, and digested the new residuum with two gros of liquid ammonia. The residuum was then filtered, washcd, and dricd. It weighed sixteen grains. The liquid was evaporated, and after incandescence I obtained four grains of molybdic acid. The residuum of this experiment, like those of Nos. X. XI. and XII. contained oxide of iron, alumine, and quartzy sand.

After these experiments I will not hesitate to prefer the method of separation by ammonia to that by soda, especially in operating with pure soda. For it may happen that the molybdena will enter into vitreous fusion with the foreign bodies contained in its ore, and then ammonia would not be capable of separating the molybdic acid from that combination. However, this inconvenience may be prevented by not making the fire too strong towards the end of the calcination. When the method by ammonia is properly considered, it will be readily perceived that it would be impossible to devise one more expeditious and less expensive.

The molybdena may be deprived of its sulphur without the aid of the nitric acid or of nitrate of potash. The molybdic acid formed is puritied from the oxide of iron with which it is naturally united, and from the quartz and argil with which they are accidentally mixed, by digesting it with ammonia; which can be done only with difficulty by means of nitric acid. Molybdate of ammonia is decomposed by a heat of incandescence, which separates from it the alkali in the state of purity and without being decomposed. It may therefore be collected without great loss in a distilling apparatus, and the acid, almost without any decrease, will be found in the retort. So many advantages united are certainly not to be found in any other method, not even in that of separation by soda.

By following these different indications we are led to the following process, which is the most advantageous for preparing molybdic acid.

New Method of preparing pure Molyldic Acid.

Take the purest sulphuret of molybdena that can be found, 
and reduce it to powder; introduce it into an inclined retort, and torrefy it, to separate the sulphur, and to oxygenate the metal, in a heat which must be immediately raised to a yery high degree. When the molybdena has lost its bri!liancy, and its black colour has changed to gray, lessen the heat, and continue to expel the last portions of the sulphur, and to complete the oxygenation of the metal at a more moderate heat, continually stirring the matter with an iron spatula. By these means the matter will be prevented from entering into fusion with the oxide of iron and a small quantity of alumine with which they are mixed, and from forming a mass which the ammonia can afterwards decompose only with difficulty, and nothing will remain adhering to the crucible. The mineral is then to be reduced to a very fine powder, and it must be digested several times with a sufficient quantity of liquid ammonia to extract the whole molybdic acid. The different liquids are then to be united, and being poured into a glass retort are distilled to dryness. Molybdate of ammonia will remain in the refort. The heat is increased to incandescence, in order to expel the ammonia. If the retort be too large, the matter must be removed into a smaller.

This process would not answer where it is required to analyse ore of molybdena. In this case it would be necessary to oxygenate the sulphur and the metal by the help of nitric acid. This method will contribute in all probability to ameliorate and render easier the analysis of sulphuret of molybdena.

\section{Addition to the preceding Experiments.}

I had undertaken four times, and with the same success, the separation of the molybdic acid by the help of ammonia in the proportions of experiment XIV, when in treating in this manner a pretty large quantity of calcined molybdena I obscrved a surprising phanomenon which hitherto I had not remarked. I separated the acid from two ounces of molybdena by the help of ammonia. The filtered liquor was left at rest for some days, to see whether any thing would be deposited; which actually was the case. Some flakes which exhibited the same phxnomena as oxide of iron were deposited. I again placed the liquor on one side, to see whether a new separation would take place. I had, however, evaporated and decomposed a quantity of the solution of molybdate of aminonia equal to a sixteenth part of the whole liquid. The residuum exhibited the same phanomena 
phænomena exactly as that obtained in experiment XIV, and was pure molybdic acid. Numerous occupations prevented me from undertaking new experiments with the solution of molybdate of ammonia until six weeks after. Having evaporated the solution to dryness, I put the saline mass into a new Hessian crucible in order to expel the ammonia by incandescence. To my great astonishment I observed that the mass deprived of ammonia, which under other circumstances fuses so readily, and which, after being some time in fusion, penetrates into the substance of the crucible, could not this time be brought into fusion even in the strongest white heat, and was only softened, emitting vapours of molybdic acid. On examining the cooled mass, I found at its surface several irregular depressions. It had an argentine splendour inclining to gray. On its fracture it exhibited a cupreous blue colour of sted with a metallic tint; its texture was scaly and very compact; it was difficult to be broken and pulverized. Its specific gravity was 5050 . By pouring over it moderately concentrated sulphuric acid the mass acquired a considerable heat, emitting nitrous gas in abundance, and transforming itself into white oxide.

After all these phænomena, it can be considered only as metallic molybdena, or oxide of molybdena very near to the metallic state. I can explain this in no other manner than by admitting, that in consequence of the long contact of the ammonia with the molybdic acid the latter was decomposed. I dare not, however, assert that this was actually the case, and that some other cause which I did not observe may not have concurred to produce the same effect. However this may be, it is remarkable that under the circumstances above mentioned the molybdic acid, the reduction of which is so difficult, should be reduced so easily and by so weak a fire; and that the metallic molybdena, which is so little fusible, should be fused, or at least softened into a homogeneous mass of a scaly texture. The want of molybdena has hitherto prevented me from making the experiments necessary to ascertain the cause of this singular effect. 